\title{
The moron comes of age
}

Nichole Cumby, ${ }^{1}$ Alan R. Davidson ${ }^{1,2}$ and Karen L. Maxwell ${ }^{1, *}$

${ }^{1}$ Department of Molecular Genetics; University of Toronto; Toronto, ON Canada; ${ }^{2}$ Department of Biochemistry; University of Toronto; Toronto, ON Canada

Keywords: phage moron, lysogenic conversion, microbiome, superinfection exclusion, lysogen, prophage, phage HK97

Submitted: $10 / 26 / 12$

Revised: 12/05/12

Accepted: 12/06/12

http://dx.doi.org/10.4161/bact.23146

${ }^{*}$ Correspondence to: Karen L. Maxwell;

Email: karen.maxwell@utoronto.ca

Addendum to: Cumby N, Edwards AM, Davidson AR, Maxwell KL. The bacteriophage HK97 gp15 moron element encodes a novel superinfection exclusion protein. J Bacteriol 2012; 194:5012-9; PMID:22797755; http://dx.doi.org/10.1128/

JB.00843-12.
$P$ rophage-encoded genes can provide a variety of benefits for their bacterial hosts. These beneficial genes are often contained within "moron" elements. Morons, thus termed as the insertion of the DNA encoding them adds "more on" the genome in which they are found, are independent transcriptional units disseminated among phage genomes through horizontal gene transfer. Morons have been identified in the majority of phage genomes and they have been found to play diverse roles in bacterial physiology. At present, we are only beginning to ascribe functions to the many proteins encoded within these ubiquitous genetic elements. Recently, we discovered that the first described moron-encoded protein, gp15 of phage HK97, is expressed from the HK97 prophage and functions as a superinfection exclusion protein, protecting its host from genome injection by other phages. This work and the growing body of data pertaining to other morons challenges the traditional view of phages as purely parasites of bacteria and emphasizes the symbiotic relationship between bacteria and prophages.

This year, the Human Microbiome Project released a comprehensive description of the microbial communities present within humans. ${ }^{1,2}$ The increasing recognition that diverse interactions with these microbial communities plays a critical role in health and disease has led to the conclusion that an organism's genes cannot be studied in isolation when evolution occurs in the context of complex communities. Like humans, bacteria possess their own unique microbiomes, of which bacteriophages (phages) are a major component.
In fact, much of the diversity observed in closely related bacterial strains is a result of the incorporation of diverse prophages into the core bacterial genome. ${ }^{3}$ Also like the human microbiome, in which the human body is estimated to contain ten times more microbial cells than human cells, phages on earth are estimated to outnumber bacterial cells by an order of magnitude. ${ }^{4}$

While it is clear that predation by phages is a dominant factor in regulating bacterial population levels in diverse environments, ${ }^{5}$ it has also become apparent that phage-encoded genes play an important role in enhancing bacterial survival. ${ }^{6-8}$ This seeming paradox is explicable by the fact that once a phage inhabits a bacterial community its survival and propagation is dependent on the success of its host population. In fact, while some phages propogate exclusively by a lytic cycle, the majority of phages live a dual lifestyle; growing lytically some of the time, but also incorporating their genomes into their bacterial hosts and existing passively as prophages. A prophage is, in effect, a symbiont; thus, it is evolutionarily adaptive for it to express genes that enhance survival of the host. Given that the vast majority of bacterial genomes contain numerous prophages, it could be argued that most phage genomes spend the bulk of their existences as prophages. As such, the production of phage particles could be viewed as an escape mechanism from certain adverse conditions, analogous to spore production by fungal and bacterial strains. Prophage induction can be triggered a variety of host cell stressors such as DNA damage, ${ }^{9}$ changes in $\mathrm{pH}$ and temperature,${ }^{10}$ heavy metal exposure, ${ }^{10}$ oxidative stress, ${ }^{11}$ exposure to bacteriocins, ${ }^{12}$ 
and quorum sensing. ${ }^{13}$ Since survival of the prophage depends on the fitness of the bacterial host, the most successful phages will not be those that integrate silently within the genome, but those that actively protect and enhance the fitness of their host by expressing useful genes. The simple addition of a prophage to a bacterial genome thus often has significant phenotypic consequences for the host. ${ }^{7,8}$

For a prophage to maintain itself within the bacterial genome, many of its genes, such as those involved in particle formation and cell lysis, must be repressed. However, amidst this sea of repression, all prophage genomes contain small islands of expressed genes, the importance of which are becoming increasingly apparent. Many of these expressed genes lie within genetic elements that have been collectively termed "morons," which were first described by Juhala et al. in a paper comparing the genomes of $E$. coli phages HK97 and HK022. ${ }^{14}$ Within these and other related phage genomes, gene order is highly conserved such that one can identify gene function by virtue of gene position, even in the absence of sequence identity. This allowed the identification of inserted genetic elements in HK97 and HK022 that were unique to these phages. Since their presence resulted in more DNA as compared with related phages they were designated as morons. In general, morons appear as obvious additions to a phage genome; their GC content differs from the surrounding genes, implying horizontal transfer, and they have their own promoter and terminator elements to mediate expression from repressed prophages. ${ }^{14}$

The first use of the term moron related to the genetic element containing gene 15 of phage HK97, which lies in the tail operon between the genes encoding the tail tube assembly chaperone and the tape measure protein. Recently, we discovered that the product of this moron element, gp15, mediates a useful function for the host cell when expressed from a prophage. By inserting into the inner membrane this small protein prevents superinfection by other phages, including HK97 and HK75, without blocking their bacterial cell surface receptors. ${ }^{15}$ Thus, gp15 appears to prevent phage infection without affecting host cell functions mediated by the outer membrane transporters used by these phages. This exclusion is unrelated to traditional repressor-mediated immunity mechanisms since the phages it blocks belong to different immunity groups. ${ }^{15}$ Interestingly, other prophages express unrelated proteins that exploit similar entry preventing strategies for preventing phage infection. For example, the Cor proteins of E. coli phages HK022, $\mathrm{N} 15$ and $\varphi 80$ protect bacterial lysogens against other phages that require the FhuA outer membrane protein for entry by inactivating this receptor. ${ }^{16}$ This activity reduces ferrichrome uptake by cells expressing Cor, ${ }^{16}$ but it plays an additional positive role in providing protection against Colicin $\mathrm{M}$, a protein toxin that is imported through the FhuA receptor. ${ }^{17}$ The Salmonella phage P22 membranebound SieA protein blocks genome entry by phages L, MG178 and MG40 through an uncharacterized mechanism. ${ }^{18} \mathrm{We}$ observed that gp15 inhibition is independent of periplasmic and inner membrane proteins required for HK97 entry, since other phages requiring the same factors are not inhibited by gp15. However, it is dependent on features within the phage; swapping the tail regions of HK97 and HK022 is sufficient to alleviate the inhibition phenotype. ${ }^{15}$ Thus we postulate that gp15 inserts into the inner membrane of $E$. coli where it interacts directly or indirectly with the incoming phage tail to prevent it from forming a channel for the DNA through the membrane. To date, the precise mechanisms of action of gp15 are unknown.

Besides blocking phage infection and toxin import, some moron-encoded proteins provide other advantages to their bacterial hosts. For example, the prophage-expressed $\lambda$ Lom protein improves the ability of $E$. coli strains to interact with and invade human epithelial cells, ${ }^{19}$ and the Salmonella phage SopE $\Phi$ protein, SopE, secreted by the bacterial lysogen, ${ }^{20}$ leads to ruffling of the primate kidney cell membrane ${ }^{21}$ and improved invasion of human epithelial cells by Salmonella. ${ }^{22}$ Several moron-encoded proteins have been discovered that increase the ability of bacteria to survive the host immune response and proliferate in vivo. For example, the Gifsy-2 Salmonella prophage encodes a superoxide dismutase that protects the bacterium against free radicals generated by the mammalian immune system. ${ }^{23}$ The phage $\lambda$ Bor protein has similarly been demonstrated to increase the resistance of lysogenized $E$. coli to serum killing ${ }^{24}$ and the $S$. aureus phage $\varphi 13$ sak gene encodes staphylokinase, ${ }^{25,26}$ which disrupts the fibrin network that forms to keep infections localized, and degrades human IgG using a serine protease created by the activation of human plasminogen into plasmin at the bacterial cell surface. ${ }^{27}$ $S$. pyogenes phage-encoded mitogenic factors $m f 2, m f 3$ and $m f 4$ act as superantigens to trigger overproliferation of defective T-cells that are unable to bind a specific epitope of the antigen, and thus are ineffective in clearing the bacterial infection. ${ }^{28}$ Some morons encode toxin proteins that directly increase the virulence of the host. For example, shiga, diphtheria and cholera toxins which greatly enhance virulence of E. coli, ${ }^{29}$ C. diphtheria ${ }^{30}$ and $V$. cholera ${ }^{31}$ infections, respectively, are all encoded by morons. ${ }^{6}$

Other morons have been shown to help bacteria evade the immune response by modifying bacterial cell antigenicity. For example, Oac from S. flexneri phage Sf6 acetylates the $\mathrm{O}$-antigen of the bacterial lipopolysaccharide, ${ }^{32}$ thereby altering the bacterial cell surface and impairing the ability of the immune system to recognize it. ${ }^{33}$ This same alteration is also believed to protect against superinfecting phages that recognize the $\mathrm{O}$-antigen. ${ }^{34} P$. aeruginosa phage D3 is also a serotype-converting prophage; it alters the glycosidic linkages and acetylates the $\mathrm{O}$-antigen. ${ }^{35}$ These changes were demonstrated to be the result of a moron element encoding three genes: an $\alpha$-polymerase inhibitor (iap), an $O$-acetylase $(o a c)$ and a $\beta$-polymerase $\left(w z y_{\beta}\right) .{ }^{36}$ Although the two Oac proteins encoded by phages Sf6 and D3 are only $22 \%$ identical, their appearance in two quite different species of bacteria illustrates that while moron functions are diverse, the mechanisms by which they function may be conserved among phages.

In addition to conservation among phages, many of the morons discussed here have bacterial homologs found outside of prophage-encoded regions. When PSI-BLAST searches were performed 
with HK97 gp15, all homologs identified were found in Enterobacteriaceae, and the majority were not phage or prophage-encoded. The bacterial sequences belong to the YebO family, a group of proteins of unknown function. ${ }^{15}$ While the protein sequence of gp15 bears a strong resemblance to these proteins in its $\mathrm{N}$-terminal region, it is highly diverged at the C-terminus, and we found that overexpression or deletion of the E. coli YebO protein had no effect on HK97 phage propagation. Thus, we postulate that $y e b O$ was inserted into the phage genome by horizontal gene transfer, and diverged over time until it acquired the new function of providing phage resistance. Similar to gp15, oac of Pseudomonas phage D3 has a number of bacterial homologs, including Pseudomonas WbpC proteins, with which it shares $32 \%$ sequence identity. ${ }^{37}$ The phage D3 Oac protein plays the same role as that from S. flexneri phage Sf6, but the D3 protein is approximately twice as large (687 vs. 333 residues). Analysis of the closest homologs of each of these phage proteins reveals that they are bacterial in origin. Coupled with the large difference in the size of the proteins, this suggests that these proteins were independently

\section{References}

1. Human Microbiome Project Consortium. A framework for human microbiome research. Nature 2012; 486:215-21; PMID:22699610; http://dx.doi. org/10.1038/nature11209.

2. Human Microbiome Project Consortium. Structure, function and diversity of the healthy human microbiome. Nature 2012; 486:207-14; PMID:22699609; http://dx.doi.org/10.1038/nature11234.

3. Ahmed SA, Awosika J, Baldwin C, Bishop-Lilly KA, Biswas B, Broomall S, et al.; Threat Characterization Consortium. Genomic Comparison of Escherichia coli O104:H4 Isolates from 2009 and 2011 Reveals Plasmid, and Prophage Heterogeneity, Including Shiga Toxin Encoding Phage stx2. PLoS One 2012; 7:e48228; PMID:23133618; http://dx.doi org/10.1371/journal.pone.0048228.

4. Bergh O, Børsheim KY, Bratbak G, Heldal M. High abundance of viruses found in aquatic environments. Nature 1989; 340:467-8; PMID:2755508; http:// dx.doi.org/10.1038/340467a0.

5. Suttle CA. Viruses in the sea. Nature 2005; 437:35661; PMID:16163346; http://dx.doi.org/10.1038/ nature 04160 .

6. Brüssow H, Canchaya C, Hardt WD. Phages and the evolution of bacterial pathogens: from genomic rearrangements to lysogenic conversion. Microbiol Mol Biol Rev 2004; 68:560-602; PMID:15353570; http://dx.doi.org/10.1128/MMBR.68.3.560602.2004.

7. Canchaya C, Fournous G, Brüssow $H$. The impact of prophages on bacterial chromosomes. Mol Microbiol 2004; 53:9-18; PMID:15225299; http://dx.doi. org/10.1111/j.1365-2958.2004.04113.x. co-opted by phages to protect the bacterial lysogens from superinfection.

Recently, a number of effectors of the type III secretion system were discovered to be encoded in phage moron elements. For example, the $S$. enterica Gifsy-1 phage encodes $\mathrm{GogB},{ }^{38}$ which is secreted by the type III secretion system into mammalian cells where it reduces the host inflammatory response that is designed to help clear the $S$. enterica infection, thereby helping the bacteria establish a chronic infection. ${ }^{39}$ A second example is provided by the NleA-like type III effector protein of the shiga-toxin encoding phage BP-4795 which increases virulence in mouse models. ${ }^{40,41}$ Since the effector molecules are only useful when they can be secreted and phages do not encode the secretion apparatus, the genes encoding these effector proteins are likely bacterial in origin.

As the number of bacterial and phage genome sequences increases, the number and diversity of described moron elements also multiplies. In a recent study of Burkholderia pseudomallei phages, 17 unique moron-encoded protein sequences were identified, with some phages encoding as many as 12 different morons. ${ }^{42}$ These moron elements are predicted to

8. Casjens S. Prophages and bacterial genomics: what have we learned so far? Mol Microbiol 2003; 49:277300; PMID:12886937; http://dx.doi.org/10.1046/ j.1365-2958.2003.03580.x.

9. Borek E, Ryan A. Lysogenic induction. Prog Nucleic Acid Res Mol Biol 1973; 13:249-300; PMID:4267058; http://dx.doi.org/10.1016/S00796603(08)60105-1.

10. Choi J, Kotay SM, Goel R. Various physico-chemical stress factors cause prophage induction in Nitrosospira multiformis 25196--an ammonia oxidizing bacteria. Water Res 2010; 44:4550-8; PMID:20630557; http://dx.doi.org/10.1016/j.watres.2010.04.040.

11. Banks DJ, Lei B, Musser JM. Prophage induction and expression of prophage-encoded virulence factors in group A Streptococcus serotype M3 strain MGAS315. Infect Immun 2003; 71:707986; PMID:14638798; http://dx.doi.org/10.1128/ IAI.71.12.7079-7086.2003.

12. Madera C, García P, Rodríguez A, Suárez JE, Martínez B. Prophage induction in Lactococcus lactis by the bacteriocin Lactococcin 972. Int J Food Microbiol 2009; 129:99-102; PMID:19056139; http://dx.doi. org/10.1016/j.ijfoodmicro.2008.11.004.

13. Ghosh D, Roy K, Williamson KE, Srinivasiah S, Wommack KE, Radosevich M. Acyl-homoserine lactones can induce virus production in lysogenic bacteria: an alternative paradigm for prophage induction. Appl Environ Microbiol 2009; 75:714252; PMID:19783745; http://dx.doi.org/10.1128/ AEM.00950-09. encode toxin-antitoxin pairs, superinfection exclusion proteins, restriction endonucleases, and virulence factors. In addition to morons being newly identified through bacterial and phage genome sequencing efforts, there are likely previously unrecognized moron elements in sequenced and characterized phage genomes. A study examining the expression of unannotated small open reading frames ( $<50$ amino acids) in E. coli identified and characterized a number of previously unrecognized proteins. ${ }^{43,44}$ Like gp15, many of these proteins were found to localize to the bacterial cell envelope, and a number of these were found to play a role in modifying the bacterial cell in response to stress conditions such as changes in osmolarity and $\mathrm{pH} .{ }^{44}$ It is possible that a number of these small proteins may also be located within prophage genomes, but were previously not annotated due to their small size.

To conclude, it is now clear that morons are "smarter" than they originally appeared to be. First recognized merely as add-ons to phage genomes, we now realize that these frequently occurring genetic elements improve the fitness of their bacterial hosts in a wide variety of ways.

14. Juhala RJ, Ford ME, Duda RL, Youlton A, Hatfull GF, Hendrix RW. Genomic sequences of bacteriophages HK97 and HK022: pervasive genetic mosaicism in the lambdoid bacteriophages. J Mol Biol 2000; 299:27-51; PMID:10860721; http://dx.doi. org/10.1006/jmbi.2000.3729.

15. Cumby N, Edwards AM, Davidson AR, Maxwell KL. The bacteriophage HK97 gp15 moron element encodes a novel superinfection exclusion protein. J Bacteriol 2012; 194:5012-9; PMID:22797755; http://dx.doi.org/10.1128/JB.00843-12.

16. Uc-Mass A, Loeza EJ, de la Garza M, Guarneros G, Hernández-Sánchez J, Kameyama L. An orthologue of the cor gene is involved in the exclusion of temperate lambdoid phages. Evidence that Cor inactivates FhuA receptor functions. Virology 2004; 329:42533; PMID:15518820; http://dx.doi.org/10.1016/j. virol.2004.09.005.

17. Harkness RE, Olschläger T. The biology of colicin M FEMS Microbiol Rev 1991; 8:27-41; PMID:1931137; http://dx.doi.org/10.1016/0168-6445(91)90004-2.

18. Susskind MM, Botstein D, Wright A. Superinfection exclusion by $\mathrm{P} 22$ prophage in lysogens of Salmonella typhimurium. III. Failure of superinfecting phage DNA to enter sieA+ lysogens. Virology 1974; 62:350-66; PMID:4610992; http://dx.doi. org/10.1016/0042-6822(74)90398-5.

19. Vica Pacheco S, García González O, Paniagua Contreras GL. The lom gene of bacteriophage lambda is involved in Escherichia coli K12 adhesion to human buccal epithelial cells. FEMS Microbiol Lett 1997; 156:129-32; PMID:9368371; http://dx.doi. org/10.1016/S0378-1097(97)00415-1. 
20. Mirold S, Rabsch W, Rohde M, Stender S, Tschäpe $\mathrm{H}$, Rüssmann $\mathrm{H}$, et al. Isolation of a temperate bacteriophage encoding the type III effector protein SopE from an epidemic Salmonella typhimurium strain. Proc Natl Acad Sci U S A 1999; 96:984550; PMID:10449782; http://dx.doi.org/10.1073/ pnas.96.17.9845.

21. Hardt WD, Chen LM, Schuebel KE, Bustelo XR, Galán JES. S. typhimurium encodes an activator of Rho GTPases that induces membrane ruffling and nuclear responses in host cells. Cell 1998; 93:815-26; PMID:9630225; http://dx.doi.org/10.1016/S00928674(00)81442-7.

22. Wood MW, Rosqvist R, Mullan PB, Edwards MH, Galyov EE. SopE, a secreted protein of Salmonella dublin, is translocated into the target eukaryotic cell via a sip-dependent mechanism and promotes bacterial entry. Mol Microbiol 1996; 22:327-38, PMID:8930917; http://dx.doi.org/10.1046/j.13652958.1996.00116.x.

23. Figueroa-Bossi N, Bossi L. Inducible prophages contribute to Salmonella virulence in mice. Mol Microbiol 1999; 33:167-76; PMID:10411733; http:// dx.doi.org/10.1046/j.1365-2958.1999.01461.x.

24. Barondess JJ, Beckwith J. bor gene of phage lambda, involved in serum resistance, encodes a widely conserved outer membrane lipoprotein. J Bacteriol 1995; 177:1247-53; PMID:7868598.

25. Winkler KC, de Waart J, Grootsen C. Lysogenic conversion of staphylococci to loss of beta-toxin. J Gen Microbiol 1965; 39:321-33; PMID:4222155; http:// dx.doi.org/10.1099/00221287-39-3-321.

26. Coleman DC, Sullivan DJ, Russell RJ, Arbuthnott JP, Carey BF, Pomeroy HM. Staphylococcus aureus bacteriophages mediating the simultaneous lysogenic conversion of beta-lysin, staphylokinase and enterotoxin A: molecular mechanism of triple conversion. J Gen Microbiol 1989; 135:1679-97; PMID:2533245.

27. Rooijakkers SH, van Wamel WJ, Ruyken M, van Kessel KP, van Strijp JA. Anti-opsonic properties of staphylokinase. Microbes Infect 2005; 7:47684; PMID:15792635; http://dx.doi.org/10.1016/j. micinf.2004.12.014

28. Beres SB, Sylva GL, Barbian KD, Lei B, Hoff JS, Mammarella ND, et al. Genome sequence of a serotype M3 strain of group A Streptococcus: phageencoded toxins, the high-virulence phenotype, and clone emergence. Proc Natl Acad Sci U S A 2002; 99:10078-83; PMID:12122206; http://dx.doi. org/10.1073/pnas.152298499.
29. O'Brien AD, Newland JW, Miller SF, Holmes RK, Smith HW, Formal SB. Shiga-like toxin-converting phages from Escherichia coli strains that cause hemorrhagic colitis or infantile diarrhea. Science 1984; 226:694-6; PMID:6387911; http://dx.doi. org/10.1126/science.6387911.

30. Freeman VJ. Studies on the virulence of bacteriophage-infected strains of Corynebacterium diphtheriae. J Bacteriol 1951; 61:675-88; PMID:14850426.

31. Waldor MK, Mekalanos JJ. Lysogenic conversion by a filamentous phage encoding cholera toxin. Science 1996; 272:1910-4; PMID:8658163; http://dx.doi. org/10.1126/science.272.5270.1910.

32. Clark CA, Beltrame J, Manning PA. The oac gene encoding a lipopolysaccharide $\mathrm{O}$-antigen acetylase maps adjacent to the integrase-encoding gene on the genome of Shigella flexneri bacteriophage Sf6. Gene 1991; 107:43-52; PMID:1720755; http://dx.doi. org/10.1016/0378-1119(91)90295-M.

33. Simmons DA. The immunochemistry of Shigell flexneri lipopolysaccharides. A quantitative analysis of their monosaccharide constituents. Biochem J 1966; 98:903-8; PMID:5911535.

34. Lindberg AA, Wollin R, Gemski P, Wohlhieter JA. Interaction between bacteriophage Sf6 and Shigella flexner. J Virol 1978; 27:38-44; PMID:357756.

35. Kuzio J, Kropinski AM. O-antigen conversion in Pseudomonas aeruginosa PAO1 by bacteriophage D3 J Bacteriol 1983; 155:203-12; PMID:6190794.

36. Newton GJ, Daniels C, Burrows LL, Kropinsk AM, Clarke AJ, Lam JS. Three-component-mediated serotype conversion in Pseudomonas aeruginosa by bacteriophage D3. Mol Microbiol 2001; 39:1237-47; PMID:11251840; http://dx.doi.org/10.1111/j.13652958.2001.02311.x

37. Burrows LL, Charter DF, Lam JS. Molecular characterization of the Pseudomonas aeruginosa serotype $\mathrm{O}_{5}$ (PAO1) B-band lipopolysaccharide gene cluster. $\mathrm{Mol}$ Microbiol 1996; 22:481-95; PMID:8939432; http:// dx.doi.org/10.1046/j.1365-2958.1996.1351503.x.

38. Coombes BK, Wickham ME, Brown NF, Lemire S, Bossi L, Hsiao WW, et al. Genetic and molecular analysis of $\mathrm{GogB}$, a phage-encoded type IIIsecreted substrate in Salmonella enterica serova typhimurium with autonomous expression from its associated phage. J Mol Biol 2005; 348:81730; PMID:15843015; http://dx.doi.org/10.1016/j. jmb.2005.03.024
39. Pilar AV, Reid-Yu SA, Cooper CA, Mulder DT, Coombes BK. GogB is an anti-inflammatory effector that limits tissue damage during Salmonella infection through interaction with human FBXO22 and Skp1. PLoS Pathog 2012; 8:e1002773; PMID:22761574; http://dx.doi.org/10.1371/journal.ppat.1002773.

40. Gruenheid S, Sekirov I, Thomas NA, Deng WY, O'Donnell P, Goode D, et al. Identification and characterization of NleA, a non-LEE-encoded type III translocated virulence factor of enterohaemorrhagic Escherichia coli O157:H7. Mol Microbiol 2004; 51:1233-49; PMID:14982621; http://dx.doi. org/10.1046/j.1365-2958.2003.03911.x

41. Creuzburg K, Recktenwald J, Kuhle V, Herold S, Hensel M, Schmidt H. The Shiga toxin 1-converting bacteriophage BP-4795 encodes an NleA-like type III effector protein. J Bacteriol 2005; 187:84948; PMID:16321954; http://dx.doi.org/10.1128/ JB.187.24.8494-8498.2005.

42. Ronning CM, Losada L, Brinkac L, Inman J, Ulrich RL, Schell M, et al. Genetic and phenotypic diversity in Burkholderia: contributions by prophage and phage-like elements. BMC Microbiol 2010; 10:202; PMID:20667135; http://dx.doi.org/10.1186/14712180-10-202.

43. Hobbs EC, Astarita JL, Storz G. Small RNAs and small proteins involved in resistance to cell envelope stress and acid shock in Escherichia coli: analysis of a bar-coded mutant collection. J Bacteriol 2010; 192:59-67; PMID:19734312; http://dx.doi. org/10.1128/JB.00873-09.

44. Hemm MR, Paul BJ, Miranda-Ríos J, Zhang A, Soltanzad N, Storz G. Small stress response proteins in Escherichia coli: proteins missed by classical proteomic studies. J Bacteriol 2010; 192:46 58; PMID:19734316; http://dx.doi.org/10.1128/ JB.00872-09. 